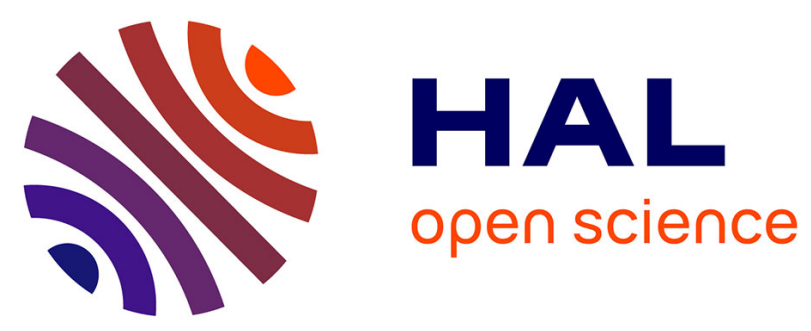

\title{
Microstructure, Texture, and Mechanical Properties of Ni-W Alloy After Accumulative Roll Bonding
}

\author{
Saadia Boudekhani, Hiba Azzeddine, Kamel Tirsatine, Thierry Baudin,
} Anne-Laure Helbert, Francois Brisset, Baya Alili, Djamel Bradai

\section{To cite this version:}

Saadia Boudekhani, Hiba Azzeddine, Kamel Tirsatine, Thierry Baudin, Anne-Laure Helbert, et al.. Microstructure, Texture, and Mechanical Properties of Ni-W Alloy After Accumulative Roll Bonding. Journal of Materials Engineering and Performance, 2018, 27 (10), pp.5561-5570. 10.1007/s11665-0183628-8 . hal-02359944

\section{HAL Id: hal-02359944 \\ https://hal.science/hal-02359944}

Submitted on 6 Dec 2019

HAL is a multi-disciplinary open access archive for the deposit and dissemination of scientific research documents, whether they are published or not. The documents may come from teaching and research institutions in France or abroad, or from public or private research centers.
L'archive ouverte pluridisciplinaire HAL, est destinée au dépôt et à la diffusion de documents scientifiques de niveau recherche, publiés ou non, émanant des établissements d'enseignement et de recherche français ou étrangers, des laboratoires publics ou privés. 


\title{
Microstructure, Texture and Mechanical Properties of Ni-W alloy after
}

\section{Accumulative Roll Bonding}

Saadia Boudekhani ${ }^{\mathrm{a},{ }^{*}}$, Hiba Azzeddine ${ }^{\mathrm{a}, \mathrm{b}}$, Kamel Tirsatine ${ }^{\mathrm{a}}$, Thierry Baudin ${ }^{\mathrm{c}}$, Anne-Laure

Helbert $^{\mathrm{c}}$, François Brisset ${ }^{\mathrm{c}}$, Baya Alili ${ }^{\mathrm{a}}$, Djamel Bradai $^{\mathrm{a}}$

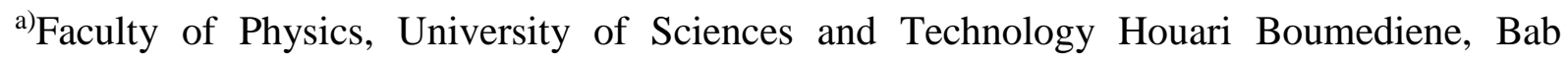
Ezzouar, BP32, El Alia, Algiers, Algeria

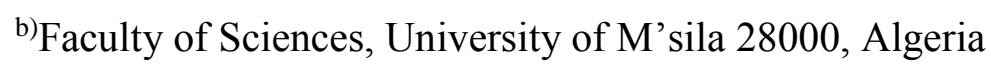

${ }^{c}$ ICMMO, SP2M, Univ. Paris-Sud, University Paris-Saclay, UMR CNRS 8182, 91405 Orsay

Cedex, France

*Corresponding author: abbas.usthb@ hotmail.fr

\begin{abstract}
In this study, the microstructure, texture, and mechanical properties evolution of Ni-14W (wt. $\%$ ) alloy processed up to four cycles of accumulative roll-bonding (ARB) were investigated using electron backscatter diffraction, microhardness measurements, and tensile tests. The initial equiaxed grains, with an average size of $10 \mu \mathrm{m}$, underwent a strong refinement after ARB processing. The elongated ultrafine grains were parallel to the rolling direction, with a grain thickness of $0.2 \mu \mathrm{m}$. The texture after ARB processing was characterized by the typical rolling components (Copper, S and Brass), which showed a tendency toward stabilization after four cycles. The microhardness increased substantially $(+86 \%)$ and seemed to saturate after three cycles. The tensile tests demonstrated that Ni-14W samples subjected to ARB processing exhibited high strength (> $1200 \mathrm{MPa}$ after three ARB cycles) and very poor ductility.
\end{abstract}

Keywords: Ni-W alloy, Grain refinement, Accumulative Roll Bonding, Microstructure, Texture

\section{Introduction}

In the past decades, $\mathrm{Ni}-\mathrm{W}$ alloy has been chosen as a suitable substrate material due to its excellent physical property and easy formation of a Cube texture following heavy straining by rolling and subsequent annealing [1-3]. The fraction of Cube-oriented grains depends strongly on the texture components resulting from prior hot or cold rolling (CR), as well as 
the stacking fault energy. Microstructural heterogeneities, such as lamella, Cube, and shear bands also play a decisive role in the Cube-texture germination and growth [4].

Ultrafine-grain microstructures have been shown to improve the strength and toughness of the material. Severe plastic deformation is one of the most effective methods for producing ultra fine-grain structures. This process can lead to significant changes in the crystallographic texture and microstructure compared with conventional processing techniques, such as compression, extrusion, or rolling. Accumulative roll bonding (ARB), a well-known technique, consists of rolling two sheets together (resulting in up to $50 \%$ thickness reduction), cutting, and stacking them to achieve the initial thickness. Repeating the whole process allows the material to accumulate very large strains without changing the initial dimensions of the original sheet [5].

Microstructure, texture, stored energy and mechanical properties evolution of pure Ni after ARB processing and annealing have been studied by many authors [6-12]. Comparison of the $\mathrm{ARB}$ and cold rolled (CR) pure Ni samples deformed to equivalent strain revealed that their microstructures were morphologically similar. However, the ARB microstructure was more refined and contained more high angle boundaries than the CR sample [8].

Some authors have evaluated the effect of $\mathrm{W}$ addition in $\mathrm{Ni}$ matrix on the texture, microstructure, surface morphology, and hardness of the substrates for YBCO-coated conductor applications [13-15]. They evidenced that the Ni-W alloy substrates had stronger cube texture, smaller grain size, less thermal grooving, and higher hardness, compared to those of the pure $\mathrm{Ni}$ substrates. This improvement was imparted to the presence of $\mathrm{W}$ in $\mathrm{Ni}$, which effectively strengthens grain boundary and then restricts grain growth and enhances the thermal stability of the substrates $[14,15]$.

Moreover, in a substrate that may be employed for the epitaxial growth of superconducting thin films, elongated grains in the rolling direction are desirable [16]. This results in the presence of elongated grains in the direction of the current flow in the superconducting layer, which is desirable for the brick wall model proposed by Bulaevskii et al. [17]. Eickemeyer et al. [18] obtained microstructures with elongated grains by micro-alloying nickel with silver (250-500 ppm), while cold rolling the Ni-W samples up to $95 \%(\varepsilon \sim 3)$, resulting in moderate grain refinement (down to $2-4 \mu \mathrm{m})$ [19].

ARB processing has been shown to produce elongated ultrafine-grain microstructures with a comparable strain [20]. These alloys can retain the sharpness of the Cube texture and have sufficient mechanical strength, caused by their ultrafine-grain microstructure $[2,15]$. 
In fact, Bhattacharjee et al. [6] have proposed to use ARB processing for improvement in the quality of cube texture in $\mathrm{Ni}$ based alloys for further coated superconductor applications. However, this approach seems to be technically impossible since industrially produced $\mathrm{Ni}$ substrate tapes obey special dimensions (70-100 $\mu \mathrm{m}$ thickness and hundreds of meters long). It should be quite problematic to process $\mathrm{Ni}$-based alloys via ARB since this technique is cyclic and requires wire-brushing, stacking and rolling. In other hand, a second paradox that may discredit the use of this technique is the fact that, subsequent recrystallization annealing at high temperatures $\left(\geq 1000^{\circ} \mathrm{C}\right)$ to obtain a strong cube texture will lower the high strength achieved during ARB processing.

According to the author's knowledge, ARB processing and annealing of Ni-W alloys in order to achieve elongated ultrafine-grain Cube-oriented microstructures and suitable mechanical properties has seldom been reported in the literature. Therefore, in spite of the antagonistic points raised above, this study is an attempt to highlight the effect of-severe plastic deformation processing to produce submicron grains and understand the microstructure and texture evolution, as well as the mechanical properties, of Ni-W strips produced by ARB up to four cycles $(\varepsilon=3.2)$.

\section{Experimental procedure}

The material investigated in the present work was a commercial Ni-14W (wt. \%) alloy (kindly provided by APERAM alloys society, France) in the form of strips of $1 \mathrm{~mm}$ in thickness. The chemical composition of the Ni-14W alloy is presented in Table 1.

The strips were cut into $15 \times 50 \mathrm{~mm}$ rectangular pieces, degreased in acetone, and wire brushed to remove the surface oxide film and achieve a good bonding. The strips were stacked and preheated at $450{ }^{\circ} \mathrm{C}$ for $10 \mathrm{~min}$; they were then processed using the ARB technique with a two-high mill of $2.2 \mathrm{~kW}$ of power, with rolls of $67 \mathrm{~mm}$ in diameter and a rotating speed of $0.14 \mathrm{~m} / \mathrm{s}$. This process was repeated up to four ARB cycles.

The microstructure and texture were investigated using electron backscatter diffraction (EBSD) in $100 \times 100 \mu \mathrm{m} 2$ zones in the rolling direction (RD)-normal direction (ND) crosssection of the sample after mechanical and electro-polishing using A2 Struers electrolyte at 25 $\mathrm{V}$. The observation was carried out using a scanning electron microscope FEG-SEM SUPRA $55 \mathrm{VP}$ operating at $20 \mathrm{kV}$. The EBSD step size was $50 \mathrm{~nm}$. EBSD data acquisition and analysis were conducted using the Orientation Imaging Microscopy (OIMTM) software program. The grain size data were obtained using a grain tolerance angle of $5^{\circ}$, and the minimum grain size was chosen to be 5 pixels. All data points with a confidence index $(\mathrm{CI})$ 
lower than 0.05 were excluded from the analysis as dubious. (The CI quantifies the reliability of the indexed patterns). In the EBSD maps, boundaries with more than $15^{\circ}$ misorientations were defined as high-angle grain boundaries (HAGBs) and those with $2-15^{\circ}$ misorientations as low-angle grain boundaries (LAGBs). The quantitative texture analysis was carried out by calculating the orientation distribution function (ODF) using MTex software [21].

The dislocation density was estimated using the Kernel Average Misorientation (KAM) method implemented in OIM software. In this method, the misorientation $\theta \mathrm{KAM}$ around the central point of a grain in relation to a defined set of nearest neighboring points is quantified. The dislocation density is then calculated using the following equation [22]:

$\rho=\frac{\alpha \theta_{K A M}}{X b}$

where $\alpha$ is a parameter that depends on the grain boundary type and is chosen to be $3, b$ is the Burgers vector $(0.24 \mathrm{~nm}$ for Ni alloys), $X=n d, \mathrm{n}=3$ for nearest neighbors, and $\mathrm{d}=50 \mathrm{~nm}$ is the EBSD scan step.

The microhardness of the material was measured after each ARB cycle using a Shimadzu G21 series facility with a diamond pyramid indenter under loading charge of $2.94 \mathrm{~N}$ and indentation time of 10 seconds. An average of 20 readings was taken near the middle of the sample's RD-TD plane to obtain the average microhardness value.

Fig. 1 shows a sketch of different analyzed zones of the NiW alloy sample. The EBSD maps were collected on the RD-ND plane while microhardeness was measured in the RD-TD plane. The room temperature tensile tests were conducted at a strain rate of 10-2 s-1 on an MTS CriterionTM facility; model C45 105, with $100 \mathrm{kN}$ as the maximum force. The ARB strips were machined to tensile specimen with dimensions of $4 \mathrm{~mm}$ in gauge width and $15 \mathrm{~mm}$ in gauge length. The tensile direction of the specimens was parallel to the RD of the deformed sheets.

\section{Results and discussion}

\subsection{Microstructure and texture of the initial state}

The orientation imaging micrographs (OIM) in the inverse pole figure (IPF map) and different boundary types obtained from the as-received Ni-14W alloys are presented in Fig. $2 \mathrm{a}$ and b, respectively. The initial microstructure is characterized by equiaxed grains with a relatively small average grain size $(\mathrm{d} \sim 10 \mu \mathrm{m})$. The LAGBs are presented in red, and the HAGBs are in blue; as shown in Fig. 2b, most of the grain boundaries are of the HAGB type (70 \%). 
Fig. 3 shows the ODF sections $\left(\square 2=0,45\right.$, and $\left.65^{\circ}\right)$ of the as-received Ni-14W alloy. The main ideal texture component positions of the FCC alloys are also presented, and their descriptions are given in Table 2. The texture before ARB processing was characterized as relatively weak, with the presence of Cube $\square 001 \square<100>$, Brass $\square 011 \square<211>$, and S $\square 123 \square<634>$ orientations. Their overall intensity was less than about 3 mrd. These microstructures and textures resulted from the industrial thermo mechanical processing of the commercial Ni-14W alloys.

\subsection{Evolution of the microstructure and texture after ARB processing}

Fig. $4 \mathrm{a}-\mathrm{d}$ present the microstructure evolution of the Ni-14W alloy after one, two, three, and four cycles of ARB processing, respectively. The grains gradually became flattened and elongated parallel to the rolling direction. The initial equiaxed grains evolved into a lamellartype morphology, and the transverse boundary spacing along the ND (grain thickness) decreased drastically. Similar microstructure observations have been reported in pure $\mathrm{Ni}$ processed by ARB at room temperature [6,8]. As shown in Fig.4 bonding during the ARB process was mostly good, but regions of incomplete bonding were found during the last cycle. Fig. 5 presents the evolution of the HAGB volume fraction and average transverse spacing as a function of the ARB cycle number. The grain thickness significantly decreased, from 10 to $0.2 \mu \mathrm{m}$, after four ARB cycles. It is worth noting that the grain spacing along the RD (not shown) evolved only slightly $( \pm 10 \%)$.

Zhang et al. [8] found that ARB processing of pure Ni led to decrease in grain thickness from $40 \mu \mathrm{m}$ to $0.6 \mu \mathrm{m}$ after four ARB cycles. It was shown that the grain thickness values were slightly heterogenic over the sample thickness. Bhattacharjee et al. [6] showed that the grain thickness after 8 ARB cycles of pure $\mathrm{Ni}$ at room temperature reached a value of $0.21 \mu \mathrm{m}$ near to the sample surface and decreased to $0.15 \mu \mathrm{m}$ close to the center of the sample. Interesting finding in the present study was that it is possible to reach a smaller grain thickness $(0.2 \mu \mathrm{m})$ with less ARB cycles (only four ARB cycles) compared to the reported literature (eight ARB cycles) $[6,8]$. Such difference could be attributed to the initial microstructure prior to the deformation, ARB processing temperature condition and the effect of $\mathrm{W}$ element.

Following Duan et al. [7], it is well known that there was a limit to structural refinement at some strain, whereby additional deformation did not further reduce the smallest dimension of the deformation features generated by a given SPD process. However, deformation at cryogenic temperatures (e.g., cryo-rolling) yields further structural refinement. 
As shown in Fig. 5, the HAGB volume fraction decreased drastically to $23 \%$ after the first ARB cycle; it then increased and seemed to saturate around 57\% after the fourth cycle. Similar trends have been already reported in the literature for Armco Iron and Fe-36Ni (wt.\%) deformed by $\mathrm{ARB}$ (at 500 and $550^{\circ} \mathrm{C}$, respectively) [20, 23], as well as AA1050 alloy deformed by ECAP at room temperature [24].

Duan et al. [10] observed a close evolution in pure commercial nickel processed at room temperature by ARB. However, their achieved saturated HAGB values were somewhat higher $(\sim 77 \%)$ than those in the present study. The lower value obtained for the present Ni-14W alloy should mainly be associated with the processing temperature and/or solute content. It may be assumed that intermediate annealing at such a warm homologous temperature $(T / T m$ 0.31) should not be in favor of an HAGBs increase at the expense of LAGBs. Indeed, ARB processing of the Fe-36Ni alloy at $550{ }^{\circ} \mathrm{C}$ [20] exhibited a close asymptotic value of HAGBs $(\sim 68 \%)$ after four cycles. The homologous temperature of this system $(T / T m \sim 0.35)$ is close to that of the Ni-14W alloy. It has been found that solute elements, such as $\mathrm{W}$ (in a $\mathrm{Ni}$ matrix), have the effect of promoting the generation of HAGBs at the expense of LAGBs [25]. However, this effect did not seem to hold in the present case. Meanwhile, no saturation in the fraction of HAGB was reported in pure Ni processed by ARB up to eight cycles [8] which showed a continuous increase from $20 \%$ after 3 ARB cycles to $60 \%$ after 8 ARB cycles. Indeed, it was demonstrated that the fraction of HAGB strongly depended on the initial grain prior to the deformation [6]. For example, when the initial grain size of pure $\mathrm{Ni}$ was $28 \mu \mathrm{m}$ the fraction of HAGB was about $60 \%$ after eight ARB cycles, while in case of starting grain size around $650 \mu \mathrm{m}$ the fraction decreased to $36 \%$ after the same number of cycles [6].

It was demonstrated that the bonding interfaces have great influence on the heterogeneity of the deformed microstructure because of the redundant shear deformation or/and wirebrushing. Indeed, Zhang et al. [8] showed that ARB processing could produce more refined microstructure and high fraction of HAGB compared the cold rolling due to the presence of great number of subsurface layers in the ARB sample.

Fig. 6 illustrates the ODF sections $\left(\square 2=0,45\right.$, and $\left.65^{\circ}\right)$ of the Ni-14W alloy after ARB processing up to four cycles. The presence of only FCC rolling texture components (Copper, $\mathrm{S}$, and Brass) for all ARB cycles can be observed. Similar deformation texture has been observed in pure Ni processed by ARB at room temperature $[6,7,9]$. The evolution of their volume fraction as a function of the number of ARB cycles is demonstrated in Fig. 7. It can be observed that the Brass component increased slightly during the first cycle in a comparable 
manner to the initial state, and then it continuously decreased. In contrast, Copper and S components increased with increasing ARB cycles, leading to the development of a Coppertype texture. The Cube and Brass orientations underwent a weak continuous decrease, while the Goss component remained relatively constant throughout all the cycles. Sarma et al. [15] also reported a clear texture transition from a Copper-type to Brass-type texture in cold rolled FCC Ni 1-x W x alloys at W contents > 5at.\%W (14wt.\%W). These authors demonstrated that, with increasing alloying addition $(\mathrm{Ni} 1-\mathrm{x} \mathrm{W}$, with $\mathrm{x}=0,5.0,7.5$, and 9.0 at. \% corresponding to $\mathrm{x}=0,14.15,20.25$, and $23.65 \mathrm{wt}$. \%, respectively), the stacking fault energy of the alloys decreased, and finally, the deformation texture changed from a pure metal or Copper-type texture to a predominantly Brass-type texture. Indeed, Duan et al. [10] reported that the deformation texture components of pure commercial nickel processed by ARB at room temperature increase with the increase in ARB cycles, saturating after six cycles; the exception was the Copper component, which was further strengthened up to eight cycles.

Moreover, Zhang et al. [9] investigated the heterogeneity of the texture through the thickness of the deformed Ni samples. Strong rolling texture was found in the intermediate and center layers of the deformed sample, whereas shear texture are observed near the surface [9]. The rolling texture near to the interface bounding was found to be weak because of the presence of additional shear deformation [12]. Such heterogeneity of the texture in the ARB sample will affect the final recrystallization texture, i.e. the amount of Cube component. Mishin et al. [12] reported that near the interface bounding the cube texture is consistently lower than in the core of the pure Ni deformed by ARB and annealed in air at $220^{\circ} \mathrm{C}$. The small fraction of the cube texture in the interface bounding subsurface was attributed to low nucleation density of cube-oriented grains because of the presence of the shear texture [12].

It has been reported that the typical Copper-type texture can give rise to an extremely strong Cube orientation $\{001\}<100>$ following optimized recrystallization annealing [26]. In a previous work, the stored energy of the texture components in invar alloy processed by ARB varied in the order of ECopper $>$ ES $>$ EBrass $>$ ECube [27]. The amount of stored energy will favor Cube growth during recrystallization by providing the suitable driving force for a Cube grain boundary migration that invades the neighboring matrix [22, 27]. The correlation between the orientation dependency of the stored energy and the microstructure and texture on annealing was studied by Azzeddine et al. [27]; they demonstrated that the annealed sample showed a rapid decrease in Copper and $\mathrm{S}$ deformed grains and a slow decrease rate for Brass deformed grains during the annealing treatment. The present results show that the volume fraction of the S component was close to $25 \%$. This component is essential for the 
development of a sharp Cube recrystallization texture because of the high mobility of the $40^{\circ}<111>$ grain boundary between these two orientations [19].

The increase in the Copper and S components during deformation could be strongly affected by the deformation conditions. On the one hand, extensive simulations of texture evolution during cold rolling have predicted that deviation from the plane-strain state near the surface leads to the introduction of friction-induced shear components [28]. When these components were considered in the relaxed constraint model (which allows all types of shear to take place in the sheet plane), strong Copper and S components developed [28, 29]. On the other hand, during ARB processing, the shear components present in the surface regions of the samples rotated toward rolling components as soon as they moved to the quarter-thickness regions; at this point, they were subjected to plane strain deformation [20].

\subsection{Microstructure and texture after intermediate annealing}

Fig. $8 \mathrm{a}$ and $\mathrm{b}$ demonstrate the Ni-14W microstructure after ARB processing up to one and two ARB cycles, respectively, and annealing at $450{ }^{\circ} \mathrm{C}$ for $10 \mathrm{~min}$. The HAGB volume fraction and grain thickness $(l)$ are shown in Table 3. Fig. 8 illustrates that the microstructure was extremely similar to that of the deformed one after intermediate annealing (Fig. 4), which exhibited lamellar-type morphology. However, the HAGB volume fraction and grain thickness increased slightly compared with those after one and two ARB cycles (Fig. 5), which may have been due to the occurrence of recrystallization during the intermediate annealing. The results reported by Liu et al. [30] suggested that intermediate annealing of Ni9.3W (at. \%) substrates could optimize the homogeneity of the deformation microstructure.

Fig. 9 presents the ODF sections at $\square 2=0,45$, and $65^{\circ}$ of the Ni-14W alloy after ARB processing and annealing at $450{ }^{\circ} \mathrm{C}$ for $10 \mathrm{~min}$. Interesting features are depicted in this figure, which are associated with the cyclic attenuation of the main rolling components (S, Copper and Brass) and their reappearance, especially in terms of the $S$ and Copper components. During the intermediate annealing, the Cube component developed at the expense of $\mathrm{S}$, Copper, and Brass. The Cube orientation is less sharp in the second cycle. The behavior of the principal rolling components may explain why only the $S$ and Copper components notably increased with increasing ARB cycles, while the Brass component increased much less and stabilized soon after the second ARB cycle. Such observations are in good agreement with those of Liu et al. [30], who found that high intermediate annealing temperatures (without undergoing recrystallization during intermediate annealing) will sharpen the Copper-type components of the deformation texture. 


\subsection{Evolution of the mechanical properties after ARB processing}

Fig. 10a presents the evolution of the Vickers microhardness of the Ni-14W alloy after ARB processing up to four cycles. The improvement of the microhardness was as high as $86 \%$ (Hv 220 of as-received alloy and Hv 410 after four ARB cycles). The hardnening of this alloy is manifestly higher than in pure Ni processed by $\mathrm{ARB}$ at room temperature $(\mathrm{Hv} \approx 232 \mathrm{after}$ three cycles) [8]. The net increase of the microhardness could be attributed to the increase in dislocation density and concomitant grain refinement [20, 23]. The evolution of dislocation density as a function of the number of ARB cycles measured by KAM approach is shown in Fig. 10b, which shows that the dislocation density increased from $1.081015 \mathrm{~m}$-2in the asreceived alloy to $4.671015 \mathrm{~m}-2$ after three ARB cycles. After three cycles, the microhardness tended to stabilize. This stabilization can mainly be attributed to the effect of the steady-state generation of the dislocations and their annihilation. As shown in Fig. 10b, the dislocation density seems to have reached a saturated value after three ARB cycles. This steady state of the dislocation generation and annihilation was also synergistically accompanied by a stabilization of the grain spacing, as shown in Figs. 3 and 4. The latter was due to grain fragmentation and subdivision hindrance with increasing strain. The grain boundary multiplication following from this fragmentation acted as dislocation barriers, limiting the free mean path.

Fig. 11 illustrates the true stress-strain curves obtained from the tensile tests of the Ni-14W alloy after ARB processing up to four cycles. The data related to the tensile properties are summarized in Table 4. It is clear that the ultimate tensile strength (UTS) value improved. It increased from 800 to $1240 \mathrm{MPa}$ after three ARB cycles, registering a $55 \%$ improvement. The increase of the strengthening of NiW alloy with increasing ARB cycles could be attributed to the decrease of grain boundaries spacing [8]. However, the UTS decreased to $1145 \mathrm{MPa}$ after four ARB cycles. This lower tensile strength indicates some degree of flow softening. These results are explained by an insufficient strong bonding between the layers, especially at the interface formed during the last ARB cycle. It should be noted that during the tensile test, those weak interfaces, are suitable sites for crack nucleation and propagation [31]. The yield strength of the as-received sheet was $400 \mathrm{MPa}$. It exhibited a slight increase after the first ARB cycle, and surprisingly, it reached $700 \mathrm{MPa}$ after three ARB cycles. It then dropped to a value of $640 \mathrm{MPa}$ after four ARB cycles. The elongation decreased substantially, from $20.9 \%$ to $7.25 \%$, after one ARB cycle. Then, it decreased slowly to a value near $2.94 \%$ after four ARB cycles. Similar trends have been reported in the literature [32, 33]. It is worth 
noting that the three mechanical parameters fell in the ranges of the tabulated data for $\mathrm{Ni}-\mathrm{W}$ alloys fabricated using different techniques [34-36]. Zhang et al. [8] have shown a monotonous increase of the TYS up to eight ARB cycles in pure Ni after ARB at room temperature. Its value after four ARB cycles was around $600 \mathrm{MPa}$ as found in the present study (Table 4).

The uniform elongation parameter presented in Table 4 was deduced from the stress-strain curves (Fig. 10). Hasegawa et al [37] have clearly demonstrated a reasonable agreement between the estimated value (from a dislocation dynamics approach on the basis of a concept of plastic stability) and observed ones (deduced from stress-strain curves). From Table 4, it is evident that the uniform elongation decreases rapidly after one ARB cycle to slow down around $\sim 4.4 \%$ after three ARB cycles and again a rapid drop was observed (2.9\%) after four ARB cycles. The uniform elongation reported by Zhang et al. [8] was quite lower, $~ 2 \%$.

A strong reduction in ductility of the ARB processed sheets was found, and this was also associated with the loss of their strain-hardening capacity. Indeed, it is well known that metals and alloys exhibit negligible strain-hardening behavior after SPD as a balance between the rates of dislocation generation and dislocations trapped at grain boundaries [17]. In the present study, it was clearly evidenced that the Ni-14W samples subjected to ARB processing at $450^{\circ} \mathrm{C}$ up to four $\mathrm{ARB}$ cycles exhibited ultrafine grains with high strength at the expense of ductility.

Finally, the present results are in line with Saito et al. [4] in terms of the notion that, beyond rolling, which is the most appropriate process for producing bulk materials with suitable microstructures and textures, ARB processing may also be industrially important. After the promising deformation texture obtained via ARB processing, the recrystallization texture analysis is a challenging and on-going research activity for the present authors.

\section{Conclusion}

In the present study, the microstructure, texture and mechanical proprieties of a Ni-14W alloy processed by $\mathrm{ARB}$ at $450{ }^{\circ} \mathrm{C}$ up to four cycles was investigated. The main conclusions were as follows:

The initial equiaxed grains of the Ni-14W alloy, with an average size of $10 \mu \mathrm{m}$, underwent a strong refinement down to $0.2 \mu \mathrm{m}$ of their grain thickness, showing a net elongated ultrafine grain parallel to the rolling direction after ARB processing.

The texture after ARB processing was characterized by the typical rolling components (Copper, S, and Brass), which showed a tendency toward stabilization after four ARB cycles. 
The microhardness substantially increased $(+86 \%)$ and then seemed to saturate after three ARB cycles.

The tensile tests showed that the Ni-14W samples subjected to ARB processing at $450{ }^{\circ} \mathrm{C}$ up to four ARB cycles exhibited high strength (>1200 MPa after three ARB cycles) and extremely poor ductility. However, marginal drops in the yield and tensile strength were observed after the third ARB cycle.

\section{Acknowledgements}

The authors are deeply grateful to Yanick ATEBA-BETANDA from APERAM-alloys Imphy Society, France, for kindly providing the Ni-W alloy. This work was supported in part by the international PHC-MAGHEB program No. 16MAG03.

\section{References}

[1] Y. Zhao, H. L. Suo, M. Liu, D. Liu, Y. Zhang, M. Zhou, Development of cube textured $\mathrm{Ni}-5$ at.\% W alloy substrates for coated conductor application using a melting process, Physica C 440 (2006) 10-16. https://doi.org/10.1016/j.physc.2006.03.119

[2] P.P. Bhattacharjee, R.K. Ray, Effect of processing variables on cube texture formation in powder metallurgically prepared $\mathrm{Ni}$ and $\mathrm{Ni}-\mathrm{W}$ alloy tapes for use as substrates for coated conductor applications, Mater. Sci. Eng. A 459 (2007) 309-323. https://doi.org/10.1016/j.msea.2007.02.087

[3] A. Goyal, M.P. Paranthaman, U. Schoop, The RABiTS Approach: Using Rolling-Assisted Biaxially Textured Substrates for High-Performance YBCO Superconductors, MRS Bull., 29 (2004) 552-61. https://doi.org/10.1557/mrs2004.161

[4] S. Zaefferer, T. Baudin, R. Penelle, A study on the formation mechanisms of the cube recrystallization texture in cold rolled Fe-36\%Ni alloys, Acta Mater. 49 (2001) 1105-1122. https://doi.org/10.1016/S1359-6454(00)00387-6

[5] Y. Saito, N. Tsuji, H. Utsunomiya, T. Sakai, R. G. Hong, Ultra-fine grained bulk aluminum produced by accumulative roll-bonding (ARB) process, Scr. Mater. 39 (1998) 1221-1227. https://doi.org/10.1016/S1359-6462(98)00302-9

[6] P.P. Bhattacharjee, N. Tsuji, R.K. Ray, Effect of Initial Grain Size on the Evolution of $\{001\}<100>$ Texture in Severely Deformed and Annealed High-Purity Nickel, Metallurgical and Transactions A 42 (2011) 2011-2769. DOI: 10.1007/s11661-011-0674-3 
[7] J. Q. Duan, Md. Zakaria Quadir, Michael Ferry, An Analytical Framework for Predicting the Limit in Structural Refinement in Accumulative Roll Bonded Nickel, Metallurgical and Materials Transactions A 47 (2016) 471-478. https://doi.org/10.1007/s11661-015-3240-6

[8] Y.B. Zhang, O.V. Mishin, N. Kamikawa, A. Godfrey, W. Liu, Q. Liu, Microstructure and mechanical properties of nickel processed by accumulative roll bonding, Mater. Sci. Eng. A 576 (2013) 160-166. http://dx.doi.org/10.1016/j.msea.2013.04.002

[9] Y. B. Zhang O. V. Mishin, A. Godfrey, Analysis of through-thickness heterogeneities of microstructure and texture in nickel after accumulative roll bonding, J Mater Sci 49 (2014) 287-293. DOI 10.1007/s10853-013-7703-0

[10] J. Duan, M. Z. Quadir, M. Ferry, Microstructure and Texture Evolution in Nickel During Accumulative Roll Bonding, Mat. Sci. Forum. $879 \quad$ (2017) 454-458. 10.4028/www.scientific.net/MSF.879.454

[11] Y.B. Zhang, O.V. Mishin, Stored energy and recrystallized microstructures in nickel processed by accumulative roll bonding to different strains, Materials Characterization 129 (2017) 323-328. http://dx.doi.org/10.1016/j.matchar.2017.05.024

[12] O. V. Mishin, Y. B. Zhang, A. Godfrey, Recrystallization texture in nickel heavily deformed by accumulative roll bonding, IOP Conf. Series: Materials Science and Engineering 219 (2017) 012034. doi:10.1088/1757-899X/219/1/012034

[13] J. Eickemeyer, D. Selbmann, R. Opitz, B. de Boer, B. Holzapfel, L. Schultz, U. Miller, Nickel-refractory metal substrate tapes with high cube texture stability, Supercond. Sci. Technol. 14 (2001) 152-159. https://doi.org/10.1088/0953-2048/14/3/306

[14] V. Subramanya Sarma, J. Eickemeyer, L. Schultz, B. Holzapfel, Recrystallisation texture and magnetisation behaviour of some FCC Ni-W alloys, Scripta Materialia 50 (2004) 953-957. https://doi.org/10.1016/j.scriptamat.2004.01.004

[15] V.S. Sarma, J. Eickemeyer, C. Mickel, L. Schultz, B. Holzapfel, On the cold rolling textures in some fcc Ni-W alloys, Mat. Sci. Eng. A 380 (2004) 30-33. https://doi.org/10.1016/j.msea.2004.05.024

[16] U.Gaitzsch, C.Rodig, C.Damm, L. Schultz, Elongated grains in Ni5W(Ag) RABiTS tapes, J. Alloys. Compd.623 (2015) 132-135. https://doi.org/10.1016/j.jallcom.2014.10.098

[17] L. Bulaevskii, J. Clem, L. Glazman, A. Malozemoff, Model for the low-temperature transport of Bi-based high-temperature superconducting tapes, Phys. Rev. B 45 (1992) 25452549. https://doi.org/10.1103/PhysRevB.45.2545

[18] J. Eickemeyer, D. Selbmann, R. Huehne, H. Wendrock, J. Haenisch, A. Gueth,L. Schultz, B. Holzapfel, Elongated grains in textured substrate tapes and their effect on 
transport currents in superconductor layers, Appl. Phys. Lett. 90 (2007) 012510/1-3. https://doi.org/10.1063/1.2429905

[19] P.P. Bhattacharjee, R.K. Ray, N. Tsuji, Cold rolling and recrystallization textures of a Ni-5 at. $\% \mathrm{~W}$ alloy, Acta Mater. $57 \quad$ (2009) 2166-2179. https://doi.org/10.1016/j.actamat.2009.01.015

[20] K. Tirsatine, H. Azzeddine, T. Baudin, A.L.Helbert, F. Brisset, B. Allili, D. Bradai, Texture and microstructure evolution of Fe-Ni alloy after accumulative roll bonding, J. Alloys. Compd. 610 (2014) 352-360. https://doi.org/10.1016/j.jallcom.2014.04.173

[21] F. Bachmann, R. Hielscher, H. Schaeben, Texture Analysis with MTEX - Free and Open Source Software Toolbox, Solid State Phenom. $160 \quad$ (2010) 63-68. 10.4028/www.scientific.net/SSP.160.63

[22] Y. A. Betanda, A.L. Helbert, F. Brisset, M.H. Mathon, T.Waeckerle, T. Baudin, Measurement of stored energy in $\mathrm{Fe}-48 \% \mathrm{Ni}$ alloys strongly cold-rolled using three approaches: Neutron diffraction, Dillamore and KAM approaches, Mat. Sci. Eng. A 614 (2014)193-198. https://doi.org/10.1016/j.msea.2014.07.037

[23] E. Bonnot, A. Helbert, F. Brisset, T. Baudin, Microstructure and texture evolution during the ultra grain refinement of the Armco iron deformed by accumulative roll bonding (ARB), Mat. Sci. Eng. A 561 (2013) 60-66. https://doi.org/10.1016/j.msea.2012.11.017

[24] C. Harris, P. B. Prangnell, X. Duan, in: T. Sato et al. (Eds). Proceedings of the 6th International Conference on Aluminum Alloys (ICAA6), Toyohashi, Japan (1998) 583-588. [25] T. Sadat, G. Dirras, D. Tingaud, M. Ota, T. Chauveau, D. Faurie, S. Vajpai, K. Ameyama, Bulk Ni-W alloys with a composite-like microstructure processed by spark plasma sintering: Microstructure and mechanical properties, Mater. Des. 89(2016) 11811190. https://doi.org/10.1016/j.matdes.2015.10.083

[26] V. S. Sarma, J. Eickemeyer, L. Schultz, B. Holzapfel, Recrystallisation texture and magnetization behaviour of some FCC Ni-W alloys, Scripta Mater. 50 (2004) 953-957. https://doi.org/10.1016/j.scriptamat.2004.01.004

[27] H. Azzeddine, K. Tirsatine, T. Baudin, M.H. Mathon, A.L. Helbert, F. Brisset, D. Bradai. On the stored energy evolution after accumulative roll-bonding of invar alloy. Materials $\begin{array}{lllll}\text { Chemistry } & \text { and } & \text { Physics } & \text { 408-415. }\end{array}$ https://doi.org/10.1016/j.matchemphys.2017.08.063

[28] J. Hirsch, K. Lucke, Mechanism of deformation and development of rolling textures in polycrystalline fcc metals 2, Acta Metallurgica, $36 \quad$ (1988) 2883-2904. https://doi.org/10.1016/0001-6160(88)90173-3 
[29] H. Azzeddine, K. Tirsatine, T. Baudin, A.L. Helbert, F. Brisset, D. Bradai. Texture evolution of an $\mathrm{Fe}-\mathrm{Ni}$ alloy sheet produced by cross accumulativeroll bonding. Materials Characterization 97 (2014) 140-149. https://doi.org/10.1016/j.matchar.2014.09.009

[30] J. Liu, W. Liu, G. Tang, R. F. Zhu. Int J Miner Metall Mater 21 (2014) 162-168.

[31] S.O. Gashti, A. Fattah-alhosseini, Y. Mazaheri, M.K. Keshavarz. Effects of grain size and dislocation density on strain hardening behavior of ultrafine grained AA1050 processed by accumulative rollbonding. J. Alloys. Compd. 658 (2016) 854-861. https://doi.org/10.1016/j.jallcom.2015.11.032

[32] S.S. Satheesh Kumar, T. Raghu, Tensile behaviour and strain hardening characteristics of constrained groove pressed nickel sheets, Mater. Des. 32 (2011) 4650-4657. https://doi.org/10.1016/j.matdes.2011.03.081

[33] A. Krishnaiah, U. Chakkingal, P. Venugopal, Applicability of the groove pressing technique for grain refinement in commercial purity copper, Mat. Sci. Eng. A 410-411 (2005) 337-340. https://doi.org/10.1016/j.msea.2005.08.101

[34] M. Raei, M. R. Toroghinejada, R. Jamaatia, J.A. Szpunar, Effect of ARB process on textural evolution of AA1100 aluminum alloy, Mat. Sci. Eng. A 527 (2010) 7068-7073. https://doi.org/10.1016/j.msea.2010.07.089

[35] I. Matsui, Y. Takigawa, T. Uesugi, K. Higashi, Improvement in tensile ductility of electrodeposited bulk nanocrystalline $\mathrm{Ni}-\mathrm{W}$ by sulfamate bath using propionic acid, Microelectron. Eng. 91 (2012) 98-101. https://doi.org/10.1016/j.mee.2011.10.018

[36] I. Mizushima, P.T. Tang, H.N. Hansen, M.A.J. Somers, Residual stress in Ni-W electrodeposits, Electrochim. Acta $51 \quad$ (2006) 6128-6134. https://doi.org/10.1016/j.electacta.2005.11.053

[37] T. Hasegawa, K. Okazaki, Uniform tensile elongation obtained from experiment and its estimation using dislocation dynamics parameters Mat. Sci. Eng. A 297 (2001) 266-271. https://doi.org/10.1016/S0921-5093(00)01267-3 


\section{Figures captions:}

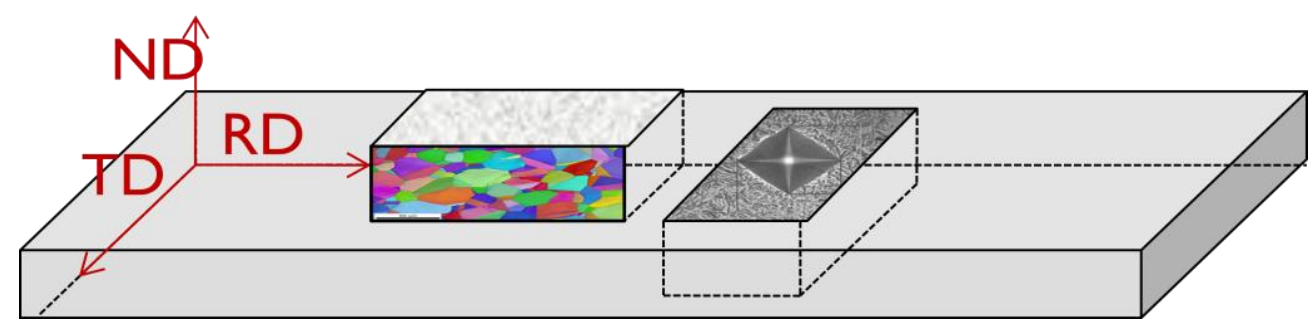

Fig. 1: Sketch of different analyzed zones of the NiW alloy sample. The EBSD maps were collected on the RD-ND plane while microhardeness was measured in the RD-TD plane.
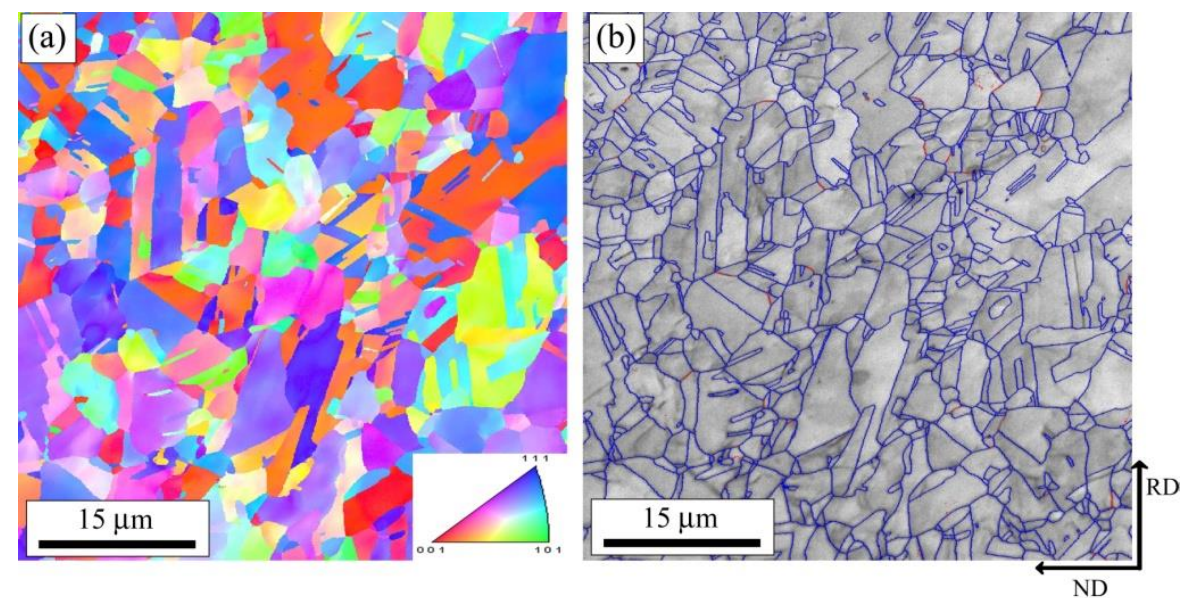

Fig. 2: OIM maps showing the microstructure of the as received $\mathrm{Ni}-14 \% \mathrm{~W}$ alloy as: a) inverse pole figure map and b) different boundary types map: LAGBs in red and HAGBs in blue.

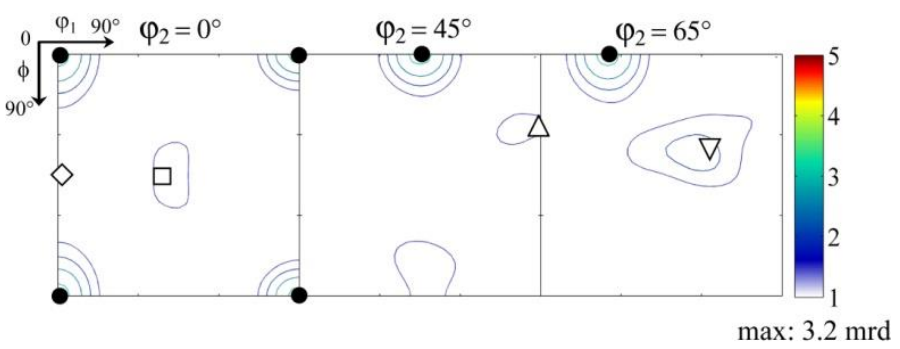

Fig. 3: ODF sections at $\varphi 2=0,45$ and $65^{\circ}$ of as received Ni-14W alloy. 

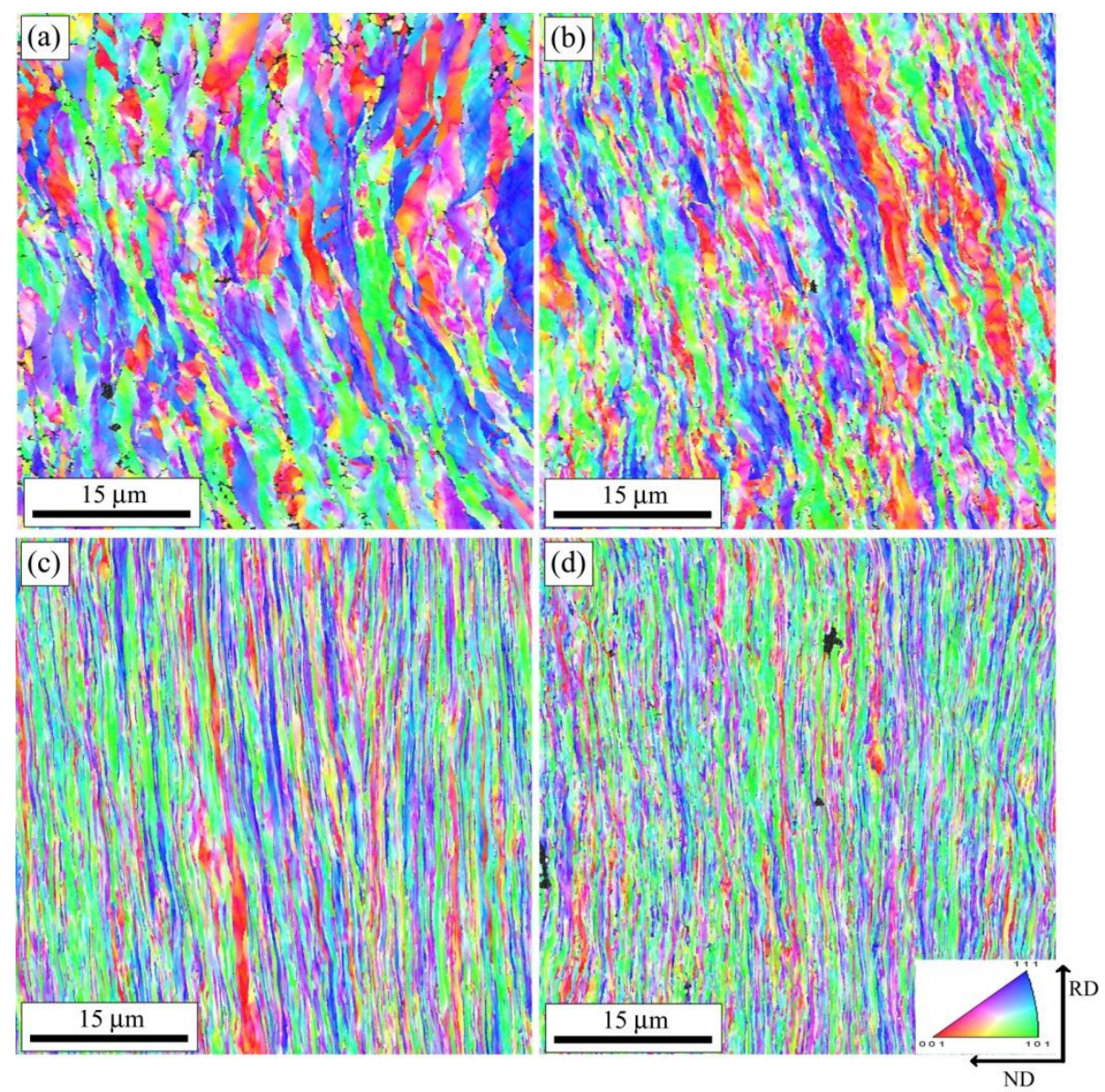

Fig. 4: IPF maps showing the microstructure evolution of Ni-14W alloy after ARB processing up : a) one cycle, b) two cycles, c) three cycles and d) four cycles.

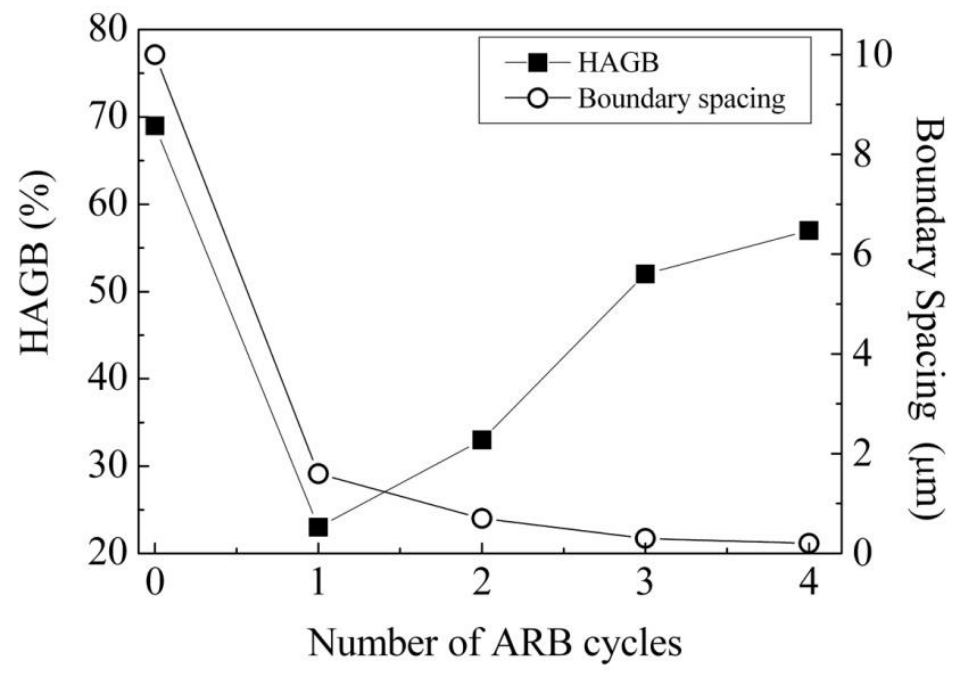

Fig. 5: Evolution of the HAGB volume fraction and average transverse spacing (along ND) of HAGBs versus the ARB cycle number. 


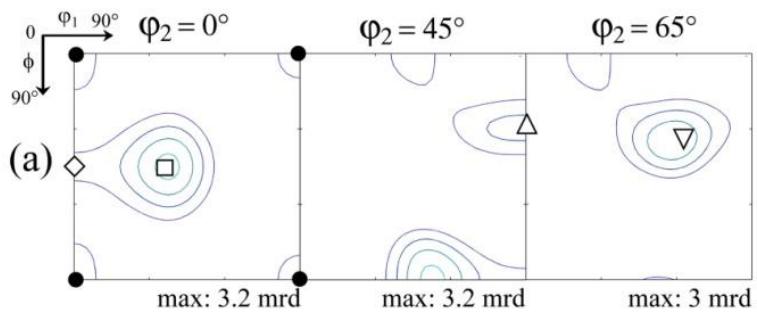

(b)

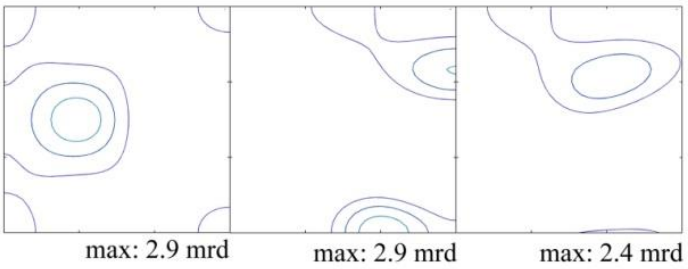

(c)

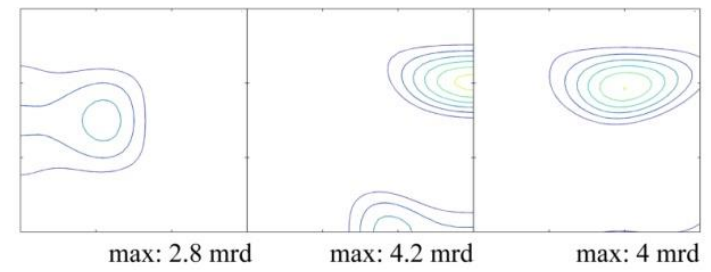

(d)

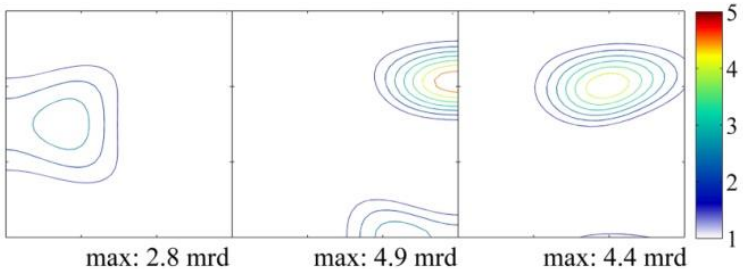

Fig. 6: ODF sections at $\varphi 2=0,45$ and $65^{\circ}$ of $\mathrm{Ni}-14 \mathrm{~W}$ alloy after ARB processing: a) one cycle, b) two cycles, c) three cycles and d) four cycles.

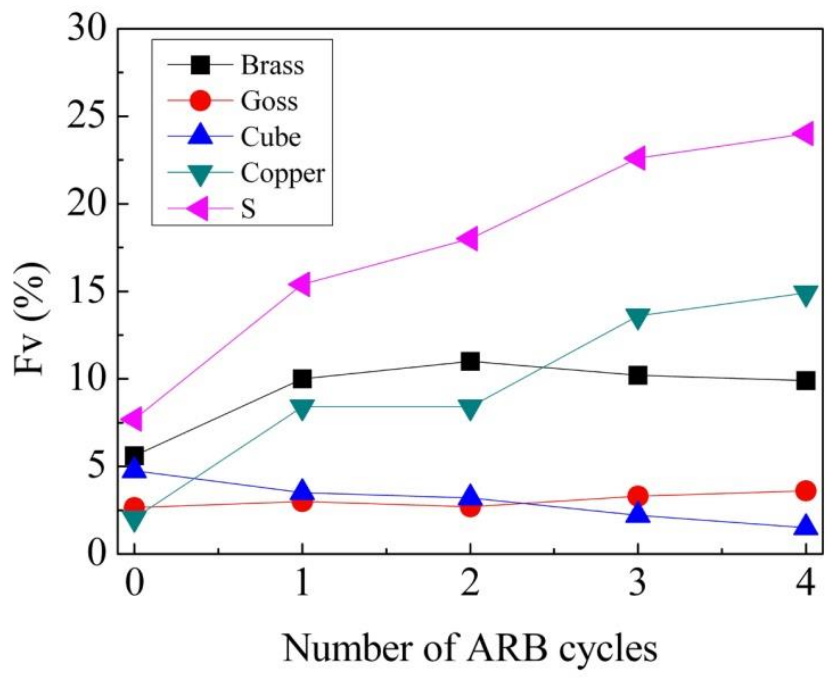

Fig. 7: Volume fraction of the texture components of the Ni-14W alloy after ARB processing.
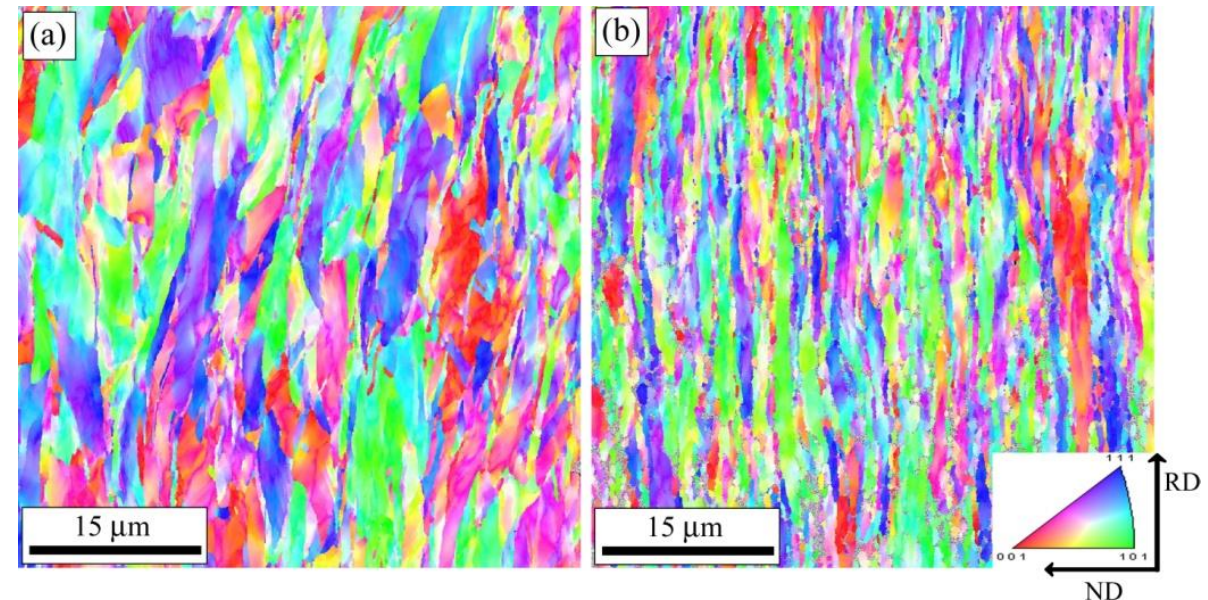

Fig. 8: IPF maps showing the microstructure evolution of Ni-14W alloy after ARB processing up : a) 1 cycle and annealed, b) 2 cycles and annealed at $450{ }^{\circ} \mathrm{C}$ for $10 \mathrm{~min}$. 


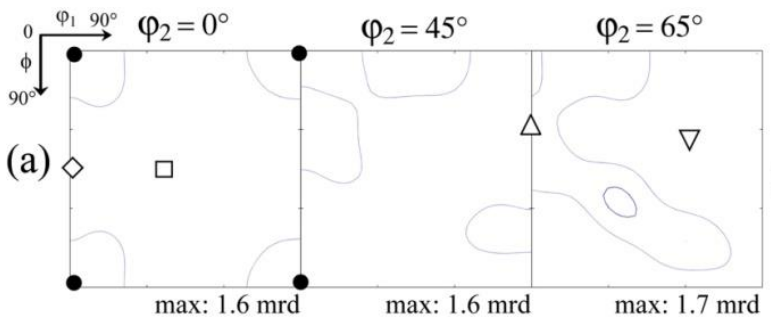

(b)

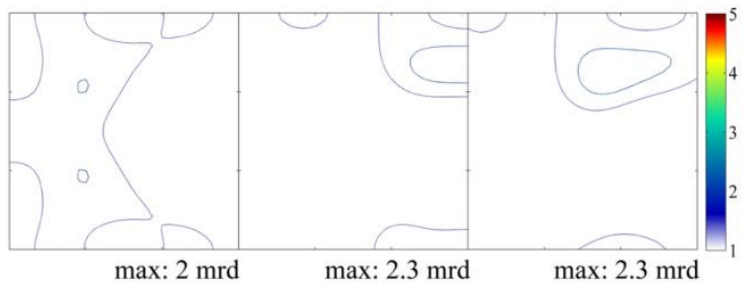

Fig. 9: ODF sections at $\varphi 2=0,45$ and $65^{\circ}$ of Ni-14W alloy after ARB processing: a) one cycle and annealed, b) two cycles and annealed at $450{ }^{\circ} \mathrm{C}$ for $10 \mathrm{~min}$.
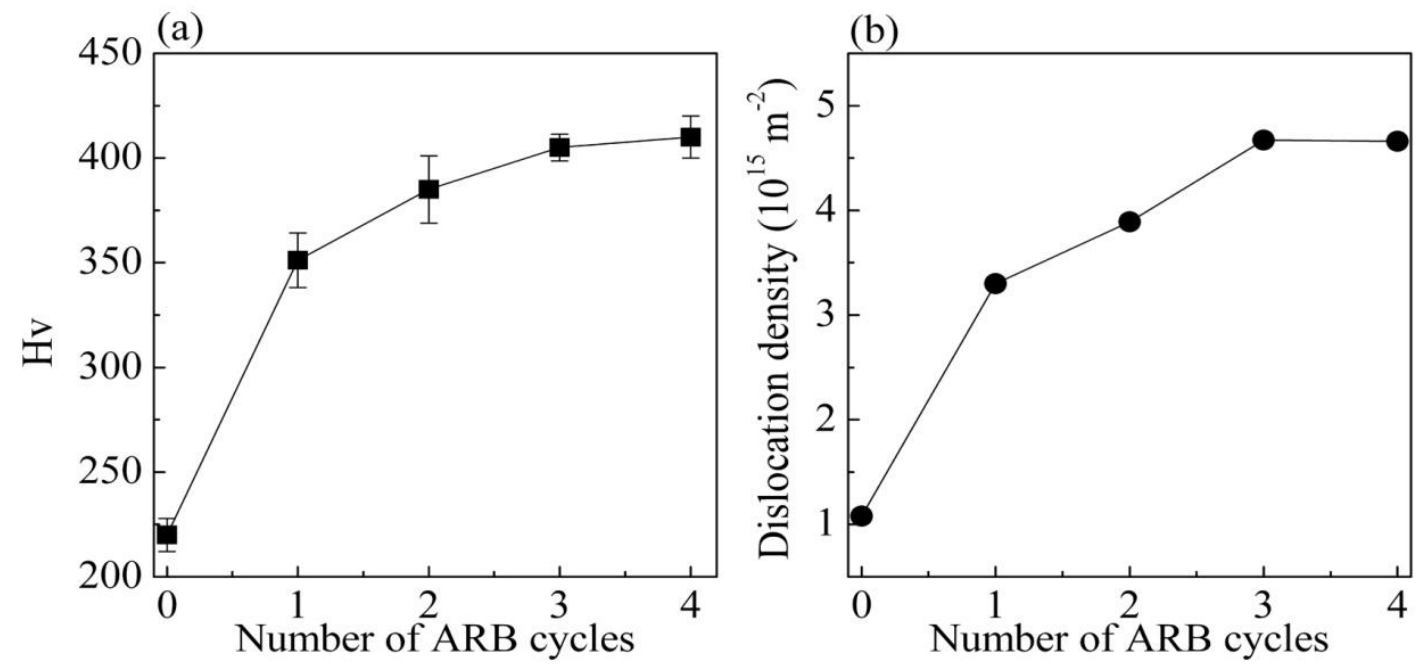

Fig. 10: a) Microhardness and b) dislocation density evolution of Ni-14W alloy after ARB processing up to four cycles.

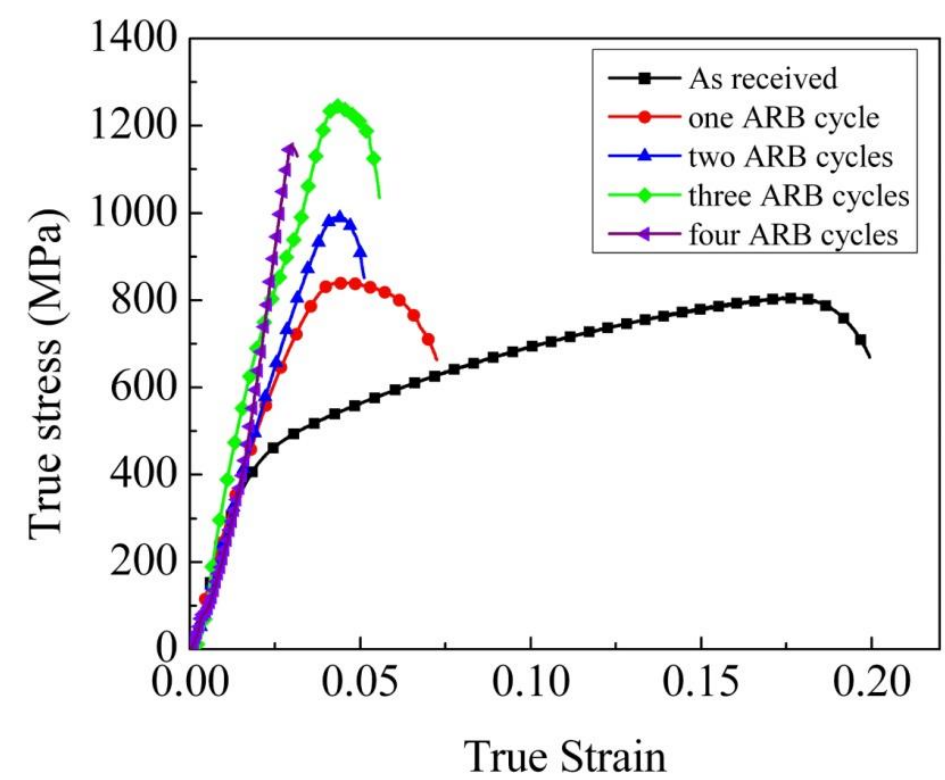

Fig. 11: True stress versus true strain of the Ni-14W alloy after ARB processing up to four cycles. 


\section{Table caption}

Table 1: Chemical composition of the Ni-14W(wt. \%) alloy.

\begin{tabular}{llllll}
\hline $\mathrm{W}$ & $\mathrm{C}$ & $\mathrm{Mn}$ & $\mathrm{Mg}$ & $\mathrm{S}$ & $\mathrm{Ti}$ \\
\hline 14 & 0.016 & 0.023 & 0.0017 & $<0.0005$ & $<0.001$ \\
\hline
\end{tabular}

Table 2: Main ideal rolling texture components of FCC alloys.

\begin{tabular}{lllll}
\hline Component & $\{$ hkl $\}<$ uvw $>$ & \multicolumn{3}{c}{ Euler Angle } \\
\cline { 3 - 5 } & & $\varphi 1$ & $\Phi$ & $\varphi 2$ \\
\cline { 3 - 5 } Grass & $\{110\}<112>$ & $35^{\circ}$ & $35^{\circ}$ & $45^{\circ}$ \\
Coss & $\{110\}<001>$ & $0^{\circ}$ & $45^{\circ}$ & $0^{\circ}$ \\
Gube & $\{001\}<100>$ & $0^{\circ}$ & $0^{\circ}$ & $0^{\circ}$ \\
Copper & $\{112\}<111>$ & $90^{\circ}$ & $35^{\circ}$ & $45^{\circ}$ \\
$\triangle$ & $\{231\}<346>$ & $59^{\circ}$ & $29^{\circ}$ & $63^{\circ}$ \\
\hline
\end{tabular}

Table 3: HAGBs volume fraction and grain thickness $(l)$ of Ni-14W alloy after intermediate annealing at $450{ }^{\circ} \mathrm{C}$ for $10 \mathrm{~min}$.

\begin{tabular}{lll}
\hline & $l(\mu \mathrm{m})$ & HAGB $(\%)$ \\
\hline 1 ARB + annealing & 1.57 & 26 \\
2 ARB + annealing & 0.9 & 39 \\
\hline
\end{tabular}

Table 4: Tensile yield strength (TYS), ultimate tensile strength (UTS), uniform elongation and elongation to fracture (Ef) of the Ni-14W alloy after ARB processing up to four cycles.

\begin{tabular}{lllll}
\hline & TYS $(\mathrm{MPa})$ & UTS $(\mathrm{MPa})$ & Uniform elongation $(\%)$ & Ef $(\%)$ \\
\hline As received & 400 & 800 & 19.72 & 20.9 \\
1 cycle & 500 & 840 & 4.91 & 7.25 \\
\hline
\end{tabular}




\begin{tabular}{lllll}
\hline 2 & 520 & 990 & 4.49 & 5.12 \\
3 & 700 & 1240 & 4.39 & 5.44 \\
4 & 640 & 1145 & 2.94 & 2.94 \\
\hline
\end{tabular}

